\title{
On the Infiltration of Ideological and Moral Education in Primary Mathematics Teaching
}

\author{
Qin Wang ${ }^{1, a}$ and JiangJing Xia ${ }^{2, b}$ \\ ${ }^{1}$ Wuhan University of Technology, Wuhan 430070, China \\ ${ }^{2}$ Wuhan University of Technology, Wuhan 430070, China \\ a1483268805@qq.com, ${ }^{\mathrm{b}} \mathrm{m} 13277058001 @ 163 . c o m$
}

Keywords: Ideological and moral education, primary school mathematics, infiltration

\begin{abstract}
Primary school is the initial stage of the formation of a person's outlook on life, values and morality. During this period, the ideological and moral education of students is directly related to the students' ideological and moral standards and personality construction. Primary mathematics teaching not only has a certain role of knowledge inheritance, but also has a certain role in moral education. The infiltration of moral education in mathematics teaching not only improves the ability of mathematical knowledge, but also improves the comprehensive quality of students effectively. According to the students' existing knowledge base, actively looking for the best combination of moral education and mathematics knowledge, well-designed teaching content, grasp the opportunity of teaching, utilizing the characteristics of mathematics to excavate the ideological and moral education contents contained in mathematics, and realizing mathematics teaching and the combination of ideological and moral education is an important issue in primary school mathematics education.
\end{abstract}

\section{Introduction}

Syllabus for primary school: "when students master basic knowledge, they develop intelligence, improve their ability and receive ideological and moral education.". Primary school mathematics is a very important discipline in elementary education. As a primary school mathematics teacher, we can not just teach but not educate people. While teaching mathematics knowledge, we should also educate students on ideological and morality so that students can become ideal, moral, Cultural, disciplined newcomers. Education, which includes teaching and educating people, bears the hope of the nation and the future of the nation. It is the duty of every teacher to educate the students well. Primary school mathematics teachers in the process of teaching should strive to ideological and moral education throughout the entire teaching of mathematics. Herbart once said: "I can't imagine teaching without education, just as I don't admit to any teaching without education." In the process of mathematics teaching infiltration of ideological and moral education, to improve students' moral cognition, cultivating students' noble sentiments, temper their willpower, encourage them to develop good habits, which is the essential character of quality education.

\section{Improving Students' Cognitive Level in Primary School Mathematics Teaching}

In the teaching process of primary mathematics, we should fully tap the content of moral education contained in mathematics, raise students' moral cognition, and enable students to establish a correct outlook on life, values and morality. First, using textbooks. Sukhomlinski once said: "In any subject, students should be taught moral education." In the primary school mathematics textbooks, a number of reading materials are arranged, including the historical materials of mathematics, the stories of mathematicians, mathematics in practical life, the mystery of mathematics and so on. Primary school mathematics teachers in the classroom teaching activities to fully tap the textbooks behind the rich cultural atmosphere, both to deepen the students' understanding of mathematics, but also to carry out moral edification of students through the 
glorious deeds of celebrities. Second, in a good classroom teaching atmosphere to improve students' moral awareness. Personal most sincere feelings are easy to impress others, the expression of the idea can be accepted by others. In the process of teaching mathematics in primary school, the teacher should make an exemplary role to regulate their own teaching seriously every word and action, rigorous attitude, full respect for personality development and the special differences of students, treat every student with equal, easygoing attitude, enable students to accept the teacher's education consciously in the process of identifying teachers, improve their level of moral cognition. Penetration of moral education in primary school mathematics, must not be applied mechanically, far fetched some truth, single preaching to the students, but should actively explore the teaching materials contained in the educational factors, to find ideological and moral education and knowledge to teach the best fit , grasp the opportunity to carefully design the teaching content, so that primary school mathematics classroom can always flashed the spark of ideological and moral education, illuminate the child's mind. So that students in the process of learning mathematics, not only can learn knowledge, more importantly, learn to think, learn to know, learn to be a man.

\section{Infiltration of Emotional Education in Primary School Mathematics Teaching}

"Primary school mathematics curriculum teaching standards," said: "In the whole process of primary school mathematics teaching students should infiltrate moral education." Mathematics curriculum standards that emotional, attitudes, values is one of the goals of mathematics courses[1]. In the process of mathematics teaching, through reasoning, passion, to strengthen the ideological and moral education of students. Tao Xingzhi said: "The whole mystery of educating children lies in believing in children and liberating children." In the primary school mathematics teaching process, we should pay attention to discover the advantages and strengths of children, fully tap the potential of children, stimulate their enthusiasm for learning.[2].Suhomlinski said: "Only to stimulate students to self-education education, is the real education." In the process of mathematics teaching, we should pay attention to the use of appreciation of education to express the recognition of students, encourage students to keep making progress, let them learn in a pleasant atmosphere, enhance self-efficacy, to redouble their efforts to achieve greater success in learning. In the study of the number of prime and the number of composite, we introduced the great mathematician Chen Jingrun to the students and proved Goldbach's conjecture through painstaking studies. He made great contributions to the leading position of our mathematics in the world. However, he has not been so proud of himself, It owes his achievements to the motherland and the people. To introduce the glorious deeds of outstanding mathematicians at home and abroad can inspire students to glorify the patriotic enthusiasm for the country, so that students from childhood to establish a national prosperity, national revitalization and hard work, courageous struggle to cultivate students' national pride and patriotism[3]. In every aspect of the teaching process, each of the knowledge points of the professor, but also through the "infiltration point" timely conduct ideological and moral education for students, and cultivate their good quality. For example, in the study of scores, through the hole into the pool of this well-known story into the knowledge point, to the students about what is the score, in the teaching of mathematical knowledge at the same time so that we learn Kong Rong respect for the good old age, learn humility and friendship. In teaching students how to watch the clock when you can be extended to the education of students in the study and life to the scientific and reasonable arrangements for time, there must be time planning consciousness, can not waste time, learn to do the master of time. In the explanation of the water resources utilization, afforestation, garbage bag recycling and other mathematical examples, they can be deepened to expand, to tell students that China is a populous country, water resources, environmental pollution is serious, as the country's small master, saving water Resources, to protect the environment, do not litter, love the public vegetation, is the obligation of each of us. Therefore, the teaching process of primary school mathematics is not only the cognitive process of imparting knowledge, but also the emotional process of opening up students' minds. Infiltrating emotional education in mathematics teaching can improve the teaching effect of mathematics and promote the development of students' 
moral character.

\section{Temper students' will in primary school mathematics teaching}

With the deepening of the concept of quality education, educators found that will quality in a person's learning, life and growth process plays an important role in adversity when even play a decisive role. Now the children in the process of growing up is mostly smooth, did not experience too much frustration, the process of doing things inevitably lack of perseverance. Mathematics is a rigorous discipline, with a strong logic and scientific, understanding of mathematical knowledge to solve mathematical problems must go through a complex process, is a difficult, indomitable will behavior. Therefore, in the teaching process of mathematics, we can consciously have a plan to cultivate students' strong will. The formation of good will can be through the following aspects: First, the power of example. In the process of learning mathematics, the children will learn from the books a lot of celebrities, such as Archimedes, Zu Chongzhi, Curie, Hua Luogeng, Chen Jingrun and so on. Teachers in the teaching of mathematical knowledge can also use these mathematicians, scientists great glory to affect students, so that students know that the science of the road is never smoothly, the courage to overcome the difficult behavior and strong learning perseverance is the key to the success of a person, so as to enable students to correct bad thoughts and bad habits consciously to form a good self-control. Second, training students' will in stimulating students' interest in learning. Mathematics is not only a basic discipline, but also a learning tool, It is closely related to our daily life and production. The best way to educate them is to start from their side of the phenomenon of life, starting from the outside to the inside, from the near to the distant from here, from low level to high level, from perceptual to rational, and guide students in life observation, thinking and practice, to solve practical problems in using different methods, and improve the consciousness the students in the learning process to stimulate students' interest in learning, so as to improve the students' learning will. Third, set the difficulties, temper the will. Man's will is not inborn, but gradually develops through the overcoming of difficulties in the process of production and practice of the acquired life. Soviet educator Vygotsky put forward the theory of the zone of proximal development, he believes that teaching should focus on the recent developments in the area, bring the teaching content, the difficulty for the students in the teaching process, the only way to stimulate the potential of students, and fully mobilize the enthusiasm and initiative of students, which go beyond its existing and development to the next stage stage of development. In the teaching process of mathematics teachers in primary school, according to Vygotsky's theory of zone of proximal development, set up a certain degree of difficulty in the concrete situation of the subject can consciously plan, guide students to overcome their own suffering. In this process, students are constantly encouraged by emotion, so that students can feel the pleasure of learning in their own will. Einstein said: "Excellent character and steel will be more important than wisdom and erudition." While learning mathematics well, developing students' good will quality is of great importance to the formation of healthy psychology and personality.

\section{Cultivating Students' Good Behavior Habits in Primary School Mathematics Teaching}

Bacon once said: "Habit is a kind of tenacious and tremendous power, which can dominate the life of a person. Therefore, a good habit of behavior should be cultivated through education at an early age." In the course of mathematics teaching, Specific vivid examples for students to master the knowledge, feel the charm of mathematics learning. Mathematics is a discipline with strict logic, which requires students to have a serious, rigorous and scientific attitude[4]. Practice has proved that the establishment of good behavior habits need to undergo rigorous training, mathematical calculations must not tolerate the slightest mistake, which requires students in the calculation process must not negligence, to be patient, but also to improve the estimates and check Ability, which not only can improve the computing power, but also to cultivate careful and rigorous and good logical thinking ability. Second, teachers should encourage students to dare to question the 
difficulties, bold speculation, seeking different associations, allowing students to use different methods to solve the problem, a problem more solutions, so that students form a good learning, diligence, daring to doubt the habit of thinking, to develop students' creative talents lay a solid foundation[5]. Third, in the primary school mathematics teaching, let students through the group cooperation learning way to explore new knowledge, in the collective experience of knowledge construction process, cultivate students' team spirit and collective honor, experience unity and cooperation, overcome difficulties, success of happiness. Let students know that cooperation is a manifestation of team spirit, in learning to cooperate with each other in the future life should also cooperate with each other, the only way to achieve greater success[6].Fourth, using colorful extracurricular activities to develop students good behavior habits. Teachers should strive to educate students in extracurricular reading and social surveys. When students learn how to organize data, teachers can ask students to investigate the number of their own daily use of garbage bags, combined with the knowledge of data processing to calculate a class all the family a week, a month, a year using garbage bags, and then combine with garbage bags on the environment caused by the the pollution to protect the environment on the education of students. In this way, let the students mastered the knowledge of mathematics, but also carried out their environmental education[7]. Therefore, through these can cultivate students to develop a scientific attitude of seeking truth from facts, dare to question the spirit of suspicion and active collaboration team spirit, as they have a high degree of responsibility and have a good moral character of the socialist cause of builders and successors to lay a solid foundation.

\section{Conclusion}

With the continuous reform of the education system, the ideological and moral integration into the teaching of primary school mathematics, not only can effectively improve the efficiency of classroom teaching, more importantly, can improve the overall quality of students. Permeating the education of moral character in elementary mathematics, on the one hand, can improve the students' cognition level and infiltrate the emotional education; on the other hand, it can not only temper the students' will, but also train them to form good behavior habits. Teachers should fully realize the importance of teaching and educating people to understand the ideological and moral education of the connotation and objectives, conscious, purposeful, planned combination of the characteristics of mathematics disciplines of students ideological and moral education. Therefore, teachers in the life to learn more observation, pay more attention to deepen the teaching materials contained in the ideological and moral education factors. In primary school mathematics teaching materials, most ideological education does not occupy a significant position, which requires teachers to seriously study teaching materials in teaching content, to grasp the internal relations of various parts of the knowledge, in the overall grasp of the knowledge structure at the same time, fully tap Potential moral education materials in the material, a planned moral education throughout the study of knowledge. According to the actual mathematics, according to the psychological characteristics of age, students in accordance with their aptitude, and effectively grasp the students' thought and organic infiltration, infiltration of heart, permeability well, multi-channel and multi-level to fulfill the educational function of mathematics teaching, to achieve "wind sneaked into the night, moisten things silently" realm, help students establish a correct outlook on life and values.

\section{References}

[1] Kong Fanzhe, Zeng Zheng.Mathematics Learning Psychology [M].Peking University Press,2009 152-153.

[2] Shen Ligang. On the Appreciation Education in Primary Mathematics Teaching [J]. Read and write: Journal of Education, 2014 11(8) 204.

[3] Chang Xin. On the Infiltration of Ideological Education in Primary Mathematics [J]. Modern 
reading: Education Edition, 2013 6(10) 238.

[4] Zhang Jianhong. Infiltrating Moral Education in Primary Mathematics Teaching[J]. Jilin education: comprehensive,2016 27(48) 136.

[5] Huang Junbin. On the Infiltration of Moral Education in Primary Mathematics Teaching[J]. Education Guide,2005 23(5) 44-45.

[6] Zeng Jinjiang. Infiltration education in primary school mathematics teaching [J]. Journal of Fujian Institute of Education,2014 15(8) 58-59.

[7] Wu Xiangang. On the Infiltration of Moral Education in Primary School Mathematics Teaching[J]. Happy reading,2016 13(4) 77. 